\title{
Structural changes in lower ionosphere wind trends at midlatitudes
}

\author{
C. Jacobi ${ }^{1}$, E. G. Merzlyakov ${ }^{2}$, R. Q. Liu ${ }^{1}$, T. V. Solovjova ${ }^{2}$, and Y. I. Portnyagin ${ }^{2}$ \\ ${ }^{1}$ Institute for Meteorology, University of Leipzig, Stephanstr. 3, 04103 Leipzig, Germany \\ ${ }^{2}$ Research and Production Association "Typhoon", Institute for Experimental Meteorology, 4, Pobeda Str., \\ 249038 Obninsk, Russia
}

\begin{abstract}
Long-term variability of the mesosphere/lower thermosphere (lower E region ionosphere) since 1970 has been analyzed using wind data series obtained at Collm $\left(52^{\circ} \mathrm{N}, 15^{\circ} \mathrm{E}\right)$ using the LF drift method and at Obninsk $\left(55^{\circ} \mathrm{N}, 37^{\circ} \mathrm{E}\right)$ applying VHF meteor radar. Applying piecewise linear trend analysis with a priori unknown number and positions of breakpoints shows that trend models with breakpoints are generally to be preferred against straight lines. There is a strong indication for a change of trends in wind parameters around 1975-1980. Similar changes are also found in the lower atmosphere, e.g., in tropospheric temperatures. This indicates a coupling between atmospheric layers at time scales of decades.
\end{abstract}

\section{Introduction}

A general question discussed in the atmospheric community is, to which degree the global climate is changing, and whether there are long-term trends present in different climate parameters. While it is widely accepted that anthropogenic greenhouse warming of the atmosphere is increasing, additional variability, e.g. due to the interplay of atmospheric circulation patterns, may give rise to periods of stronger or smaller temperature increase superposed to the general trend (Swanson and Tsonis, 2009). Even in a generally warming climate, there may be periods of several years with no temperature increase (Easterling and Wehner, 2009) due to natural climate variability, which can be confused with a change in secular trends. It is therefore of general interest to analyse climate time series not only with respect to linear trends, but also to possible changes of trend parameters,

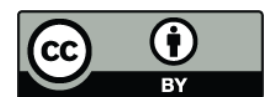

Correspondence to: C. Jacobi (jacobi@uni-leipzig.de) and to define breakpoints, when parameters of linear trend models are changing.

Time series of middle atmosphere parameters have been proposed to be useful for climate trend detection (e.g. Thomas, 1996) due to comparatively large signals, and owing to the fact that the middle and upper atmosphere is coupled with the troposphere (e.g., Kazimirovsky et al., 2003). Of particular interest in this connection have been radar measurements of the mesosphere/lower thermosphere (MLT) horizontal wind, essentially because these data are, for a few selected stations, available for several decades now. The earliest continuous measurements have started in 1953 over UK (Greenhow and Neufeld, 1961). Very long records are available from measurements at Kühlungsborn and Collm, Germany (Bremer et al., 1997) dating back to the 1950s and at Obninsk, Russia (Portnyagin et al., 2006; Merzlyakov et al., 2009) beginning in 1964. Long-term measurements over Arctic and Antarctic sites dating back to the 1960s have been presented by Portnyagin et al. (1993a, b).

Analyses of possible linear long-term trends in MLT time series have been performed, e.g., by Bremer et al. (1997). The general results were that the meridional and zonal prevailing winds were decreasing until the early 1990s, and the semidiurnal tidal (SDT) amplitudes were decreasing as well. Later, Jacobi et al. (2005) reported a linear trend in SDT phases also. The question, whether these trends are really linear, has been discussed as well. Jacobi et al. (1997) found that linear trends in Collm wind time series are changing with time. Later, applying piecewise linear trend fitting, Portnyagin et al. (2006) found trend breaks in the Obninsk and Collm wind time series around the late 1970s and the early 1990s.

Portnyagin et al. (2006) and later Merzlyakov et al. (2009) have used seasonal mean winds and tidal parameters to detect possible structural changes in long-term trends. Since the wind field, especially during the equinoxes, may vary rapidly, in this paper we will make an attempt to analyze

Published by Copernicus Publications on behalf of the URSI Landesausschuss in der Bundesrepublik Deutschland e.V. 

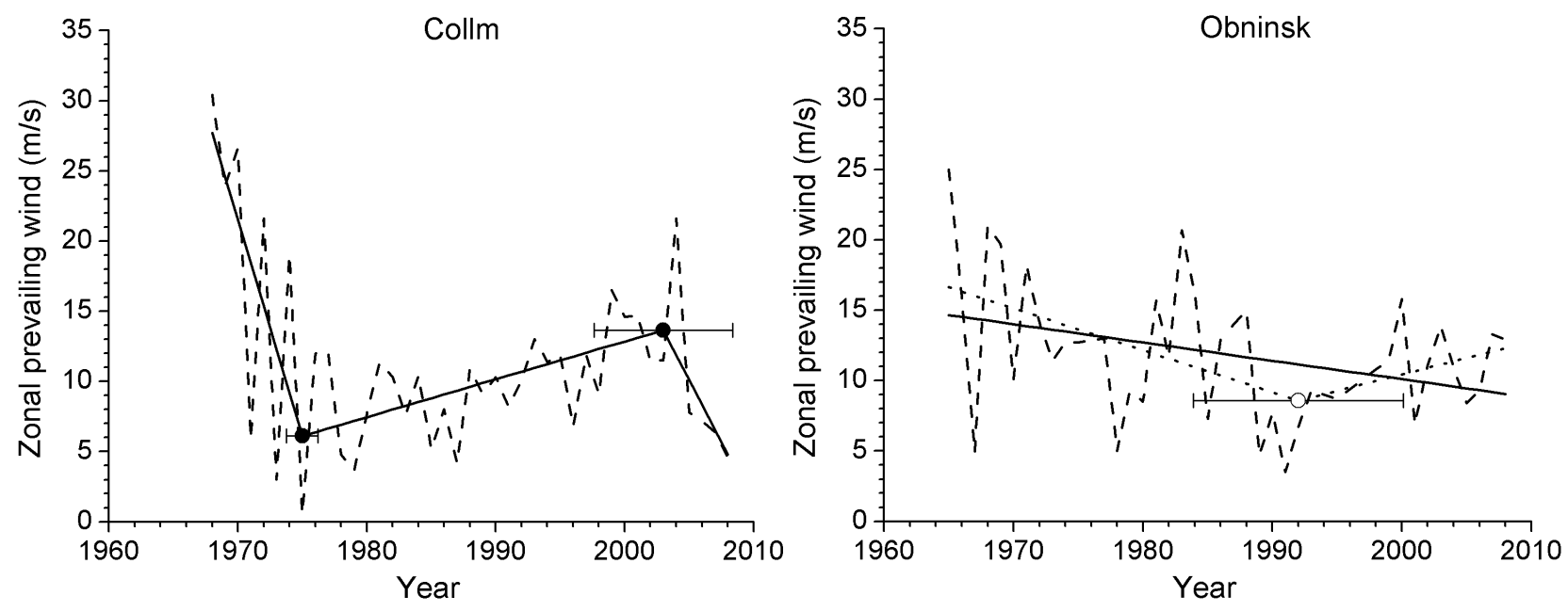

Fig. 1. January mean zonal prevailing winds (positive eastward) over Collm (left panel) and Obninsk (right panel). Results for the primary solution (solid line and symbols) and secondary solution (dashed line and open symbol) according to BIC of piecewise trend analyses are added.

long-term trends based on monthly mean winds over Collm and Obninsk. The measurements are shortly described in Sect. 2. In Sect. 3 the method for piecewise linear trend fitting is outlined. Results are presented in Sect. 4, and Sect. 5 concludes the paper.

\section{Measurements}

Two of the longest lower ionospheric wind time series presently available are used, namely winds measured at Collm $\left(52^{\circ} \mathrm{N}, 15^{\circ} \mathrm{E}\right)$ during $1968-2008$ and at Obninsk $\left(55^{\circ} \mathrm{N}, 37^{\circ} \mathrm{E}\right)$ during $1964-2007$. Both stations are located at similar middle Northern Hemisphere latitudes, at a distance of only approximately $1620 \mathrm{~km}$. The wind measurements were carried out by meteor radar without height finding at Obninsk and by the LF closely spaced receiver method at Collm.

\subsection{Collm LF lower ionospheric drifts}

At Collm Observatory, MLT winds have been obtained by D1 LF radio wind measurements from 1959-2008, using the ionospherically reflected sky wave of three commercial radio transmitters. The data are combined to half-hourly zonal and meridional mean wind values. A multiple regression analysis is used to determine the daily prevailing wind and the semidiurnal tidal wind from the half-hourly wind components assuming clockwise circularly polarized tidal wind components (Kürschner, 1991). The same method is applied to calculated monthly wind parameters using monthly median half-hourly winds (Jacobi and Kürschner, 2006). The data are attributed to the mean reflection height at about $90 \mathrm{~km}$.
The virtual reflection heights have been estimated since late 1982 using measured travel time differences between the separately received ionospherically reflected sky wave and the ground wave (Kürschner et al., 1987). This information is not used here, in order to avoid possible artifacts due to different analysis procedures before and after 1982. Data measured before 1968 have not been used, since before that date measurements have only been taken during evening hours, which do not allow an accurate discrimination between the semidiurnal tide and the mean wind. Other major changes in the measurements include a switch from manual data evaluation to automatic measurements in 1972 and the averaging of the results over three measuring paths since late 1978. Both of these changes are connected with a decrease of the statistical uncertainty, such that short-period variations are likely to be affected. However, the long-term mean wind analysis should not be affected. The Collm wind data set represents an extended dataset which has been used in Jacobi et al. (2009), however, there focus was laid on January through May means in order to compare with ozone variability. Here, we present results based on monthly mean values.

\subsection{Obninsk meteor radar winds}

Wind measurements over Obninsk using the meteor radar technique have been carried out since 1964. Frequency used is $33.3 \mathrm{MHz}$. The radar transmitting system consists of four antennas pointing in the directions N, E, S and W. For the present investigation focusing on monthly means and largescale circulation patterns the mean values of the two respective beams are considered to improve the statistical significance. The wind values are combined to hourly means. Height determination is not available and the wind values are ascribed to a height of $90 \mathrm{~km}$. The monthly mean values of 

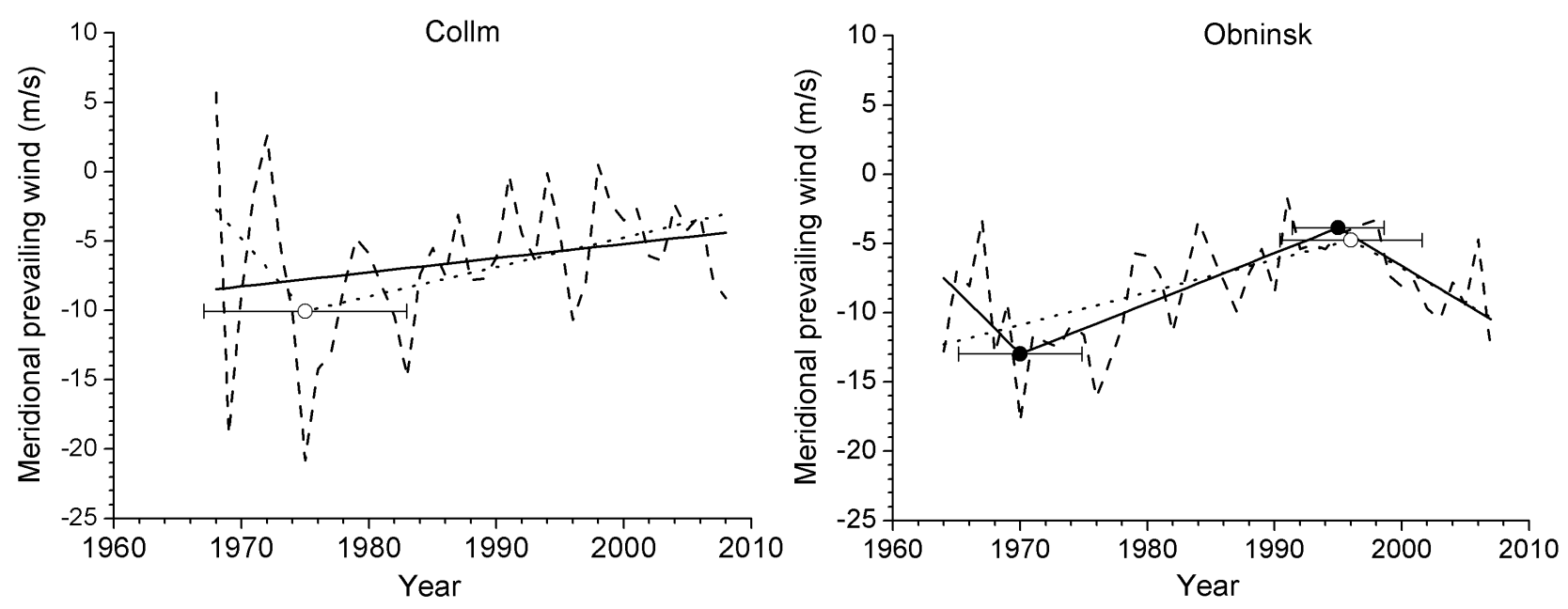

Fig. 2. As in Fig. 1, but for the June meridional prevailing winds (positive northward).
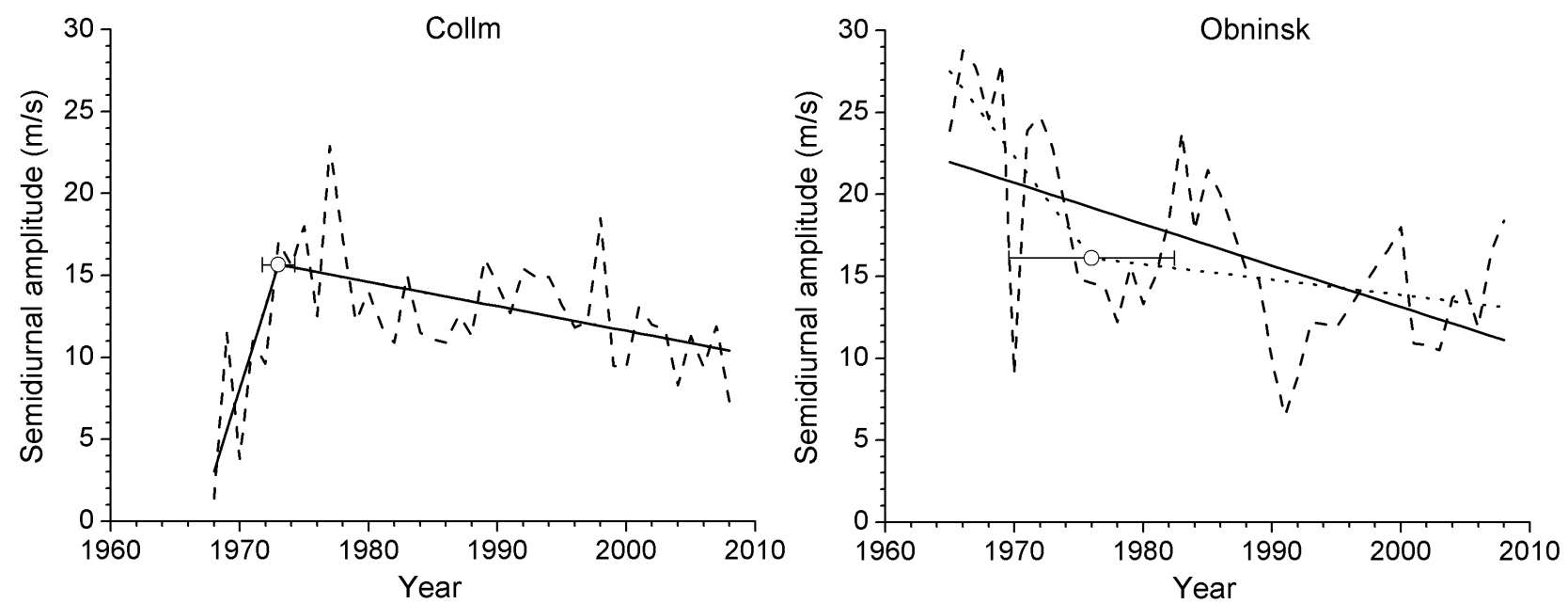

Fig. 3. As in Fig. 1, but for the January SDT amplitude.

the prevailing winds and tidal parameters are obtained from the hourly mean winds by applying a least square fitting with harmonics of $48 \mathrm{~h}, 24 \mathrm{~h}, 12 \mathrm{~h}$, and $8 \mathrm{~h}$. The root mean square errors of these means are about $1-2 \mathrm{~m} / \mathrm{s}$ except for the first four years, when they are about $3-4 \mathrm{~m} / \mathrm{s}$.

A modification of the radar in 1968 led to a significant increase of the number of meteor echoes. In 1973 the data processing procedure was modified. In addition, instrumentation and software modifications were made in the first half of the 1980s and in 1999. Each time the measurements were modified, parallel measurements using the old and the modified techniques were carried out for several months to ensure that there was no artificial shift in the data. The Obninsk wind dataset is the same as has been presented in Merzlyakov et al. (2009) and Jacobi et al. (2009), but differs in part from that one analyzed by Portnyagin et al. (2006). Some months of old wind data have been added and several monthly means have been re-evaluated. Some gaps in seasonal mean data have thus been filled.

\section{Piecewise trend analysis of time series}

In this study piecewise linear trends with a priori unknown years of breakpoints were estimated. The practical algorithm used is partly based on Tomé and Miranda (2004). The analysis was performed for different numbers of breakpoints (up to 2 , and including a linear trend model as a possibility as well) by minimizing the sum of squared residuals. To avoid edge effects, breakpoints are only considered if they are located at least 4 points from the beginning/end of the time series. Then each of the three basic trend assessments were augmented with first- and second-order autoregressive 

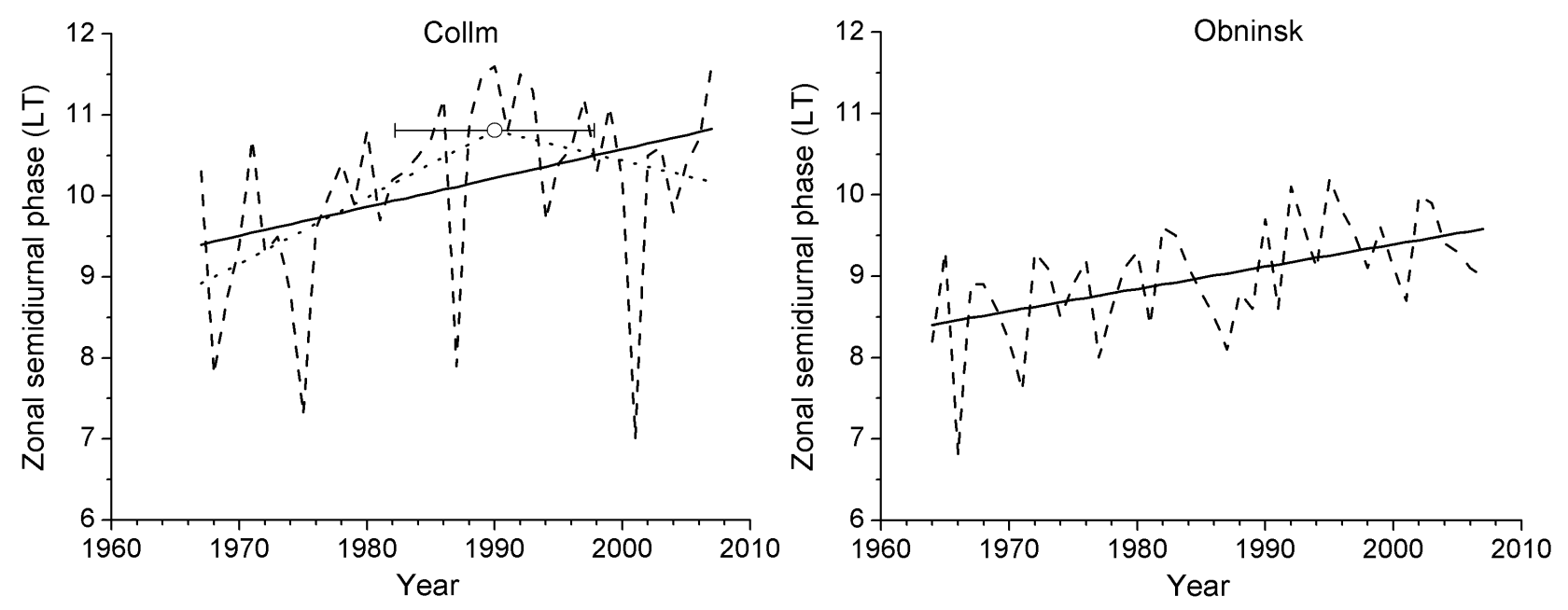

Fig. 4. As in Fig. 1, but for the November zonal SDT phase (time of maximum eastward wind in LT).

components (AR(1) and AR(2), e.g. Seidel and Lanzante, 2004). Correspondingly, the goodness of fit of the residuals to a Gaussian distribution was assessed by using the Anderson-Darling (e.g. Romeu, 2003) statistic to test the null hypothesis of normally distributed residuals. This was done with removal of the AR(1) and AR(2) behavior and with the model that does not include autoregressive behavior in the residuals $(\mathrm{AR}(0))$. Any model for which the null hypothesis is rejected at the $10 \%$ significance level (Stephens, 1974) was eliminated from further consideration. The mean value and the standard lag-one and -two autocorrelations of each accepted normally distributed residual series were calculated to check whether the residuals can be regarded as a realization of white noise. Finally, to obtain the best model, the standard form of the Schwarz-Bayesian Information Criterion (BIC, e.g. Ng and Perron, 2005; Portnyagin et al., 2006) was employed by minimizing the BIC, provided that the residuals are accepted as one-dimensional normally distributed white noise. The uncertainty of trend parameters was estimated using the Monte-Carlo simulation approach.

Note that our restriction to a maximum of 2 breakpoints is arbitrary. In the case that more breakpoints are allowed, the model tends to analyze the effect of possible decadal variations, including the 11-year solar cycle effect (e.g. Jacobi and Kürschner, 2006), which is not the topic of this analysis. The use of piecewise linear trends does not allow to consider structural changes in general (as, for example, in Merzlyakov et al., 2009), but this approach is a natural extension of the linear regression model and can be readily performed. We present results with minimum BIC and secondary solutions with second smallest BIC. Note that ranking the possible solutions according to BIC is only a statistical procedure. Other solutions may be physical as well, and the primary solutions by BIC may be non-physical, e.g. in the presence of artifacts. Therefore, the interpretation of the results has to be made with special care.

\section{Results}

In this section we present examples of time series including breakpoint analyses to provide an impression of how breakpoints are distributed. The selection of the months presented is arbitrary. Note that there are many combinations of month of year and wind parameter, where no breakpoint is found according to minimum BIC. In total, only about $10 \%$ of all time series under consideration contain breakpoints. This fact is above all owing to the relatively large variability from year to year, which is present in monthly mean time series. Analyses of seasonal means (Portnyagin et al., 2006) reveal more stable results.

In Fig. 1 January zonal mean winds over Collm and Obninsk are shown. Some similarities are visible, e.g. the decreasing trend in the early years of the measurements, which has also been reported by Bremer et al. (1997), and an increasing trend after 1990. Differences between the two time series in Fig. 1, however, are also visible, e.g. the stronger zonal winds seen in the Obninsk January time series approximately between 1980 and 1990 are visible in the Collm time series, too, but they are much weaker expressed there. Results for the primary and secondary solutions according to BIC of piecewise trend analyses are added in Fig. 1. The secondary solution for Collm is one with the same breakpoints as the primary one, but different autoregression of the residuals, so that only one trend curve is shown. Breakpoints for Collm are found in 1975 and 2003, while for Obninsk only a secondary breakpoint is found in 1992. However, if one would allow solutions with three breakpoints (not shown), the primary solution for Collm would include a third breakpoint in 1987, with error bars that overlap with the ones for the Obninsk secondary solution.

Examples for the meridional prevailing wind are shown in Fig. 2. Generally the year-to-year variability over Collm is larger than over Obninsk. This may be owing to larger 


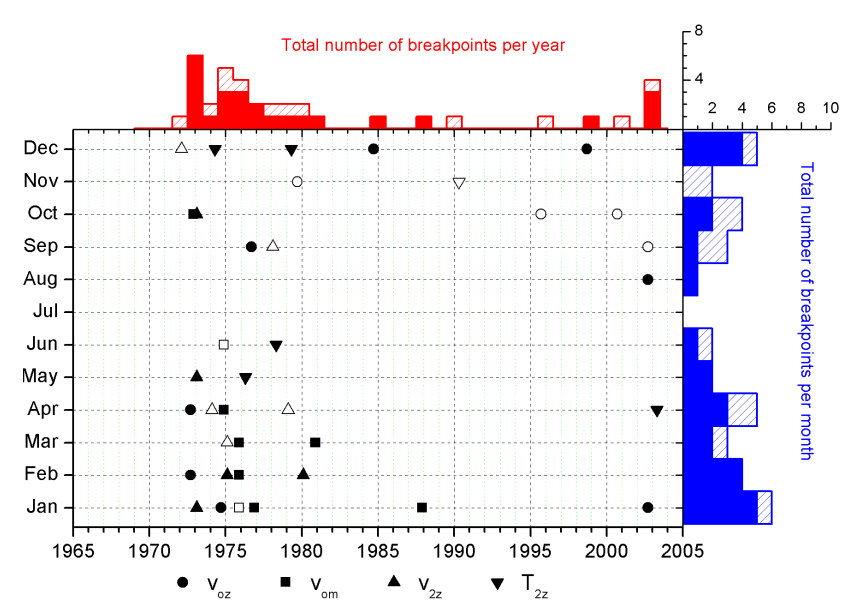

Fig. 5. Summary of breakpoints analyzed in Collm prevailing zonal $\left(V_{O Z}\right)$ and meridional $\left(V_{O m}\right)$ prevailing winds and tidal amplitudes $\left(V_{2 z}\right)$ and phases $\left(T_{2 z}\right)$. Symbols show year and month of the respective breakpoints. In the upper panel, the sum of breakpoints, for all the 4 parameters analyzed together is shown for each year. On the right hand panel the total number of breakpoints for each month is given.

uncertainty of Collm monthly means due to the long daily data gaps in summer. However, the long-term tendencies for both time series are similar. These include increase of the southward wind in the early years (note that the winds are generally negative, i.e. southward directed), a long-term decrease after $\sim 1975$, and again an increase after 1995. The latter, however, is not so clearly expressed over Collm in relation to the overall variance, so that it is not among the first two solutions selected according to minimum BIC.

The SDT phases, given as the time of eastward zonal wind maximum, generally show an increasing trend (towards later phases), which has already been noted, e.g., by Jacobi et al. (2005) and Jacobi and Kürschner (2006). As an example, the November mean phases are given in Fig. 4. Note that there is a mean difference of mean phases, which is present during the whole winter (Jacobi et al., 2005) and which may indicate that the November SDT is not only due to the migrating (westward traveling with wavenumber 2) STD, but other SDT components may be present. In the case of the November phases there is one secondary breakpoint in the Collm time series.

A summary of breakpoints seen in the Collm data series is presented in Fig. 5, while the corresponding results for Obninsk are presented in Fig. 6. A symbol is plotted in the figure each time, when a breakpoint appears in any of the time series of the zonal prevailing wind, meridional prevailing wind, SDT amplitude or SDT phase. The choice of parameters used is arbitrary, and, in order not to cram the figure with too many lines, we did not present error bars as was done in Figs. 1-4. Therefore the information that can be taken from these summaries is qualitative only. The ma-

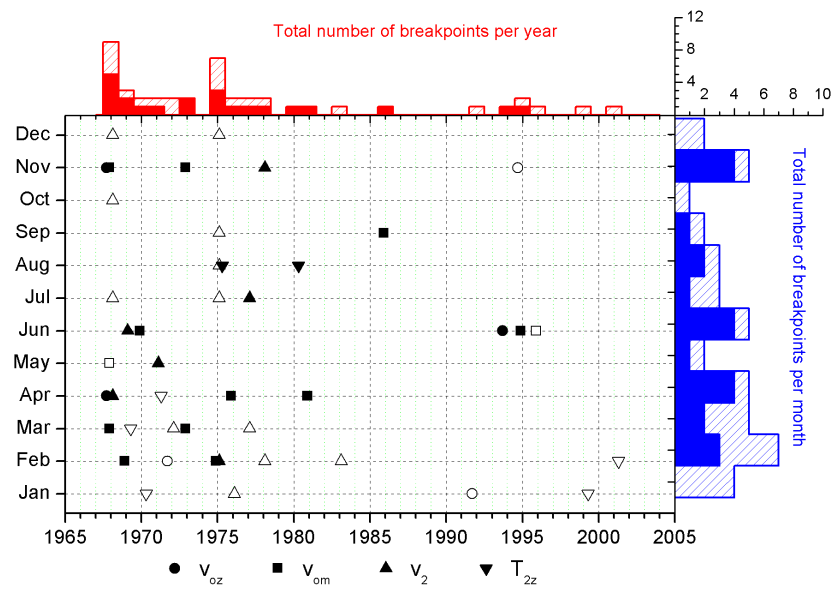

Fig. 6. As in Fig. 5, but for Obninsk winds.

jority of breakpoints is found in or after 1975. There is also a larger number of breakpoints for Collm in 1973, however, this year is very close to the change in data analysis at Collm, and may be owing to that. This idea is corroborated by the fact that in 1973 there is only one breakpoint for Obninsk. On the other hand, the 1970 breakpoints for Obninsk may be owing to artifacts in connection with the radar modification in 1968. These artifacts can be evaluated if one would take into account changes in the data variance. This might lead to a possible removal of these breakpoints. This would be a subsequent extension of the trend model. There is also some less clear clustering of breakpoints around 1995 (Obninsk only) and after 2000 (Collm only). The former possible breakpoint coincides with a change in middle atmosphere ozone, ozone laminae, and possibly temperature trend (Reinsel et al., 2005; Križan and Laštovička, 2005; Bremer and Peters, 2008). The latter breakpoint would be in correspondence with indications that the global climate has recently shifted (Swanson and Tsonis, 2009).

Only about $10 \%$ of the curves contain breakpoints according to the piecewise analysis. Taking into account that the analyses of seasonal means result in breakpoints in the majority of cases (Portnyagin et al., 2006; Merzlyakov et al., 2009), this gives rise to the conclusion, that the interannual variability of monthly means is large, and only the strongest and most robust breakpoints are found. In this case, we may conclude that there is one primary breakpoint in the time series around 1975-1980. This appears at the same time as a major change in global temperatures (e.g. Swanson and Tsonis, 2009).

For most months, large interannual variability is present, which in most cases lead to a linear (or no) trend as the best solution in the framework of piecewise linear trends. Therefore, breakpoints which have been identified in earlier analyses (Portnyagin et al., 2006; Merzlyakov et al, 2009) are not necessarily visible here. This is particularly the case with breakpoints around 1990, which are not visible in analyses 
using monthly data. We may conclude that owing to the strong variability of the MLT wind field, the use of seasonal means or more sophisticated trend models may be superior to using monthly means and piecewise linear trends, if weaker breakpoints like the one around 1990 are sought. On the other hand, especially for the equinoxes, seasonal means are not always meaningful, as they consist of averages over very different circulation patterns. This means, breakpoints that are visible in monthly means notwithstanding the large variability of these datasets, can be considered as robust.

The analysis shows that the majority of breakpoints are found roughly between 1975 and 1980. This is time interval, when a major atmospheric structural change has been observed, which is, for example, clearly visible in global temperature records. This suggests that this global change influences the dynamics of the middle atmosphere.

Acknowledgements. This study was supported by Deutsche Forschungsgemeinschaft under JA 836/22-1 and by RFBR under grant 08-05-91950. Topical Editor M. Förster thanks E. Kazimirovsky and J. Taubenheim for their help in evaluating this paper.

\section{References}

Bremer, J., Schminder, R., Greisiger, K. M., Hoffmann, P., Kürschner, D., and Singer, W.: Solar cycle dependence and longterm trends in the wind field of the mesosphere/lower thermosphere, J. Atmos. Solar-Terr. Phys., 59, 497-509, 1997.

Bremer, J. and Peters, D.: Influence of stratospheric ozone changes on long-term trends in the meso- and lower thermosphere, J. Atmos. Solar-Terr. Phys., 70, 1473-1481, 2008.

Easterling, D. R, and Wehner, M. F.: Is the climate warming or cooling? Geophys. Res. Lett., 36, L08706, doi:10.1029/2009GL037810, 2009.

Greenhow, J. and Neufeld, E. L.: Winds in the upper atmosphere, Q. J. Roy. Meteorol. Soc., 87, 472-489, 1961.

Jacobi, C., Schminder, R., Kürschner, D., Bremer, J., Greisiger, K. M., Hoffmann, P., and Singer, W.: Long-term trends in the mesopause wind field obtained from D1 LF wind measurements at Collm, Germany, Adv. Space Res., 20, 2085-2088, 1997.

Jacobi, C., Portnyagin, Y. I., Merzlyakov, E. G., Solovjova, T. V., Makarov, N. A., and Kürschner, D.: A long-term comparison of mesopause region wind measurements over Eastern and Central Europe, J. Atmos. Solar-Terr. Phys., 67, 227-240, 2005.

Jacobi, C. and Kürschner, D.: Long-term trends of MLT region winds over Central Europe, Phys. Chem. Earth, 31, 16-21, 2006.

Jacobi, C., Hoffmann, P., Liu, R. Q., Križan, P., Laštovièka, J., Merzlyakov, E. G., Solovjova, T. V., and Portnyagin, Y. I.: Midlatitude mesopause region winds and waves and comparison with stratospheric variability, J. Atmos. Solar-Terr. Phys., 71, 15401546, 2009.

Kazimirovsky, E., Herraiz, M., and De la Morena, B. A.: Effects on the ionosphere due to phenomena occurring below it, Surveys in Geophys., 24, 139-184, 2003.
Križan, P. and Laštovička, J.: Trends in positive and negative ozone laminae in the Northern Hemisphere, J. Geophys. Res., 110, D10107, doi:10.1029/2004JD005477, 2005.

Kürschner D.: Ein Beitrag zur statistischen Analyse hochatmosphärischer Winddaten aus bodengebundenen Messungen, Z. Meteorol., 41, 262-266, 1991.

Kürschner, D., Schminder, R., Singer, W., and Bremer, J.: Ein neues Verfahren zur Realisierung absoluter Reflexionshöhenmessungen an Raumwellen amplitudenmodulierter Rundfunksender bei Schrägeinfall im Langwellenbereich als Hilfsmittel zur Ableitung von Windprofilen in der oberen Mesopausenregion, Z. Meteorol., 37, 322-332, 1987.

Merzlyakov, E. G., Jacobi, C., Portnyagin, Y. I., and Solovjova, T. V.: Structural changes in trend parameters of the MLT winds based on wind measurements at Obninsk $\left(55^{\circ} \mathrm{N}, 37^{\circ} \mathrm{E}\right)$ and Collm $\left(52^{\circ} \mathrm{N}, 15^{\circ} \mathrm{E}\right)$, J. Atmos. Solar-Terr. Phys., 71, $1547-$ 1557, 2009.

Ng, S. and Perron, P.: Practitioners' corner: a note on the selection of time series models, Oxford Bulletin of Economics and Statistics, 67, 115-134, 2005.

Portnyagin, Y. I., Forbes, J. M., Fraser, G. J., Vincent, R. A., Avery, S. K., Lysenko, I. A., and Makarov, N. A.: Dynamics of the Antarctic and Arctic mesosphere and lower thermosphere regions - I. The prevailing wind, J. Atmos. Terr. Phys., 55, $827-$ 841, 1993a.

Portnyagin, Y. I., Forbes, J. M., Fraser, G. J., Vincent, R. A., Avery, S. K., Lysenko, I. A., and Makarov, N. A.: Dynamics of the Antarctic and Arctic mesosphere and lower thermosphere regions - II. The semidiurnal tide, J. Atmos. Terr. Phys., 55, $843-$ 855, $1993 b$.

Portnyagin, Y. I., Merzlyakov, E. G., Solovjova, T. V., Jacobi, C., Kürschner, D., Manson, A., and Meek, C.: Long-term trends and year-to-year variability of mid-latitude mesosphere/lower thermosphere winds, J. Atmos. Solar-Terr. Phys., 68, 1890-1901, 2006.

Reinsel, G. C., Miller, A. J., Weatherhead, E. C., Flynn, L. E., Nagatani, R. M., Tiao, G. C., and Wuebbles, D. J.: Trend analysis of total ozone data for turnaround and dynamical contributions, J. Geophys. Res., 110, D16306, doi:10.1029/2004JD004662, 2005.

Romeu, J. L.: Anderson-Darling: a goodness of fit test for small samples assumptions. Reliability Analysis Center, Selected Topics in Assurance Related Technologies, 10, 1-6, 2003.

Seidel, D. J. and Lanzante, J. R.: An assessment of three alternatives to linear trends for characterizing global atmospheric temperature changes, J. Geophys. Res., 109, D14108, doi:10.1029/2003JD004414, 2004.

Stephens, M. A.: EDF Statistics for goodness of fit and some comparisons, J. Am. Stat. Assoc., 69, 730-737, 1974.

Swanson, K. L. and Tsonis, A. A.: Has the climate recently shifted?, Geophys. Res. Lett., 36, L06711, doi:10.1029/2008GL037022, 2009.

Thomas, G. E.: Is the polar mesosphere the miner's canary of global change?, Adv. Space Res., 18, 49-58, 1996.

Tomé, A. R. and Miranda, P. M. A.: Piecewise linear fitting and trend changing points of climate parameters, Geophys. Res. Lett., 31, L02207, doi:10.1029/2003GL019100, 2004. 